\section{Bioética de intervenção, direitos humanos e justiça reprodutiva}

\author{
Sabô, Beatriz \\ Mestranda do Programa de Pós-graduação em Bioética, \\ Universidade de Brasília (UnB), Brasília, DF. Email: \\ biazsabo@gmail.com
}

\section{Manchola, Camilo}

Professor Doutor do Programa de Pós-graduação em Bioética, Universidade de Brasília (UnB), Brasília, DF. Email: camilomanchola@gmail.com

PALAVRAS-CHAVE: Bioética de Intervenção; Direitos Humanos; Justiça reprodutiva; Direitos sexuais e reprodutivos; Equidade

Introdução: A luta pelos direitos sexuais e reprodutivos conquistou inúmeros marcos legais nacionais e internacionais nas últimas décadas (1); entretanto, muito se tem focado em formas de contracepção, invisibilizando questões relacionadas também à concepção. Surgem, diante disso, reivindicações das feministas negras (2) para se pensar no conceito de justiça reprodutiva pontuando que também deve ser respeitada e defendida a escolha pelo ato de conceber, pela maternidade e pela garantia de vida digna à criança nascida. Objetivo: analisar o conceito de justiça reprodutiva pela compreensão dos direitos humanos como instrumento teórico da Bioética de Intervenção (3) entendida como uma bioética crítica, social e engajada. Metodologia: pesquisa bibliográfica em bancos de dados e bibliotecas virtuais e de pesquisa documental por material disponibilizado pelo Ministério da Saúde, pelas Nações Unidas, e pelo poder legislativo, especialmente a Lei 9.263/96, conhecida como Lei de Planejamento Familiar (4). Resultados: propõem-se os conceitos de equidade e responsabilidade estatal para a discussão de uma proposta interventiva que agregue a participação das mulheres, em especial das mulheres negras, em seu planejamento reprodutivo e que crie condições para que a escolha possa ser concretizada compreendendo que inúmeras são situações estruturais de desigualdades em um país periférico como o Brasil. A Bioética de Intervenção (5) pode ser usada como ferramenta para abordar uma preocupação recorrente entre as organizações feministas negras, relativa a obter poder sobre o próprio processo reprodutivo buscando por liberdade em relação ao corpo e vida reprodutiva e sexual e também demandando por políticas e programas que supram essas necessidades. As reivindicações apontam que não apenas são as mulheres de classes menos favorecidas, em maioria negras, as que mais sofrem e morrem em decorrência de abortos inseguros e criminalizados, mas também que são elas vítimas de esterilizações compulsórias e mortes maternas. Por assumir posição politizada e preocupada com as populações menos favorecidas e por defender que a prioridade seja a luta para colocar fim aos dilemas éticos persistentes promovendo a justiça pelo princípio da equidade, a Bioética de Intervenção se mostra apropriada para a defesa de direitos sexuais e reprodutivos para todas as mulheres, principalmente para aquelas que ainda hoje por questões de raça e classe são obrigadas a abdicar do direito de concepção. $\mathrm{O}$ conceito de justiça reprodutiva busca trazer a necessidade de diferenciar as políticas de natalidade das políticas de controle populacional e coloca no cerne da questão as condições sociais que muitas vezes proíbem essas mulheres de darem à luz. Assim, o conceito está amplamente relacionado ao conceito de justiça social e dos direitos humanos. Conclusões: os direitos humanos, como analisados pela Bioética de Intervenção, são uma ferramenta que pode visibilizar e operacionalizar o conceito de justiça reprodutiva, chamando a atenção não apenas para as questões relacionadas à contra concepção mas também à concepção, e mostrando que as esterilizações forçadas são graves violações dos direitos sexuais e reprodutivos de mulheres negras e pobres que devem ter assegurada, por políticas públicas específicas, a criação de condições para uma vivência digna e saudável da maternidade.

AGRADECIMENTOS. Agradeço ao Prof. Dr. Volnei Garrafa, ao Prof. Dr. Camilo Manchola e a Profa. Dra. Aline Albuquerque pelo apoio, incentivo, disponibilidade e contribuições. Agradeço a Universidade Brasília, especialmente ao Programa de Pós-Graduação em Bioética, pelos recursos necessários à realização do mestrado acadêmico.

\section{REFERÊNCIAS}

[1] CÔRREA, S; ÁVILA, MB. Direitos sexuais e reprodutivos: pauta global e percursos brasileiros. In: Berquó, E. (org). Sexo e Vida: panorama da saúde reprodutiva no Brasil. Campinas: Unicamp, 2003.

[2] DAVIS, Angela. Mulheres, Raça e Classe. São Paulo: Boitempo, 2016.

[3] PAGANI, L; LOURENZATTO, C; TORRES, J; ALBUQUERQUE, A. (1). Bioética de Intervenção: aproximação com os direitos humanos e empoderamento. Revista Brasileira De Bioética, 3(2), 191-217. v. 3 n. 2 (2007).

[4] BRASIL. Lei $\mathrm{n}^{\circ}$ 9.263, de 12 de janeiro de 1996. Regula o $\S 7^{\circ}$ do art. 226 da Constituição Federal, que trata do planejamento familiar, estabelece penalidades e dá outras providências.

[5] GARRAFA, V; PORTO, D. Intervention bioethics: a proposal for peripheral countries in a context of power and injustice. Bioethics 2003; 17:399-416. 